\title{
ARQUIVOS, REPRESENTAÇÕES E MEMÓRIA DOS TRABALHADORES RURAIS: litigios trabalhistas na zona canavieira de Pernambuco.
}

\author{
Cristhiane Laysa Andrade Teixeira Raposo*
}

\begin{abstract}
RESUMO: O presente trabalho pretende fazer uma análise sobre os registros dos movimentos dos trabalhadores rurais e suas representações a caminho da Justiça do Trabalho. Utilizamos nessa abordagem processos trabalhistas do arquivo do Tribunal Regional do Trabalho da $6^{\mathbf{a}}$ Região e prontuários policiais do Departamento de Ordem Política e Social de Pernambuco produzidos entre as décadas de 1970 e 1980. O objetivo é pensar a memória do trabalho a partir dos arquivos constituídos por fontes judiciais e policiais dos trabalhadores rurais da zona canavieira de Pernambuco. Os acervos vão constituir-se em fontes para análise das experiências dos assalariados e construção de uma história dos trabalhadores no campo.
\end{abstract}

PALAVRAS-CHAVE: Justiça, Trabalho, Arquivo, Memória.

\section{Archives, representations and memory of rural workers: labor conflicts in the sugar cane zone of Pernambuco}

\begin{abstract}
The present work intends to make an analysis on the archival records of rural workers' movements and their representations on the way to Labor Justice. We used labor lawsuits from the archive of the Regional Labor Court of the 6th Region and police records of the Department of Political and Social Order of Pernambuco, produced between the 1970s and 1980s.. The objective is to think the memory of the work from the archives constituted by judicial and police sources of the rural workers of the canavieira zone of Pernambuco. The collections will constitute sources for the analysis of the experiences of wage earners and the construction of a history of workers in the countryside.

KEYWORDS: Justice, Work, Archive, Memory.
\end{abstract}

\section{Archivos, representaciones y memoria de trabajadores rurales: conflictos laborales en la zona canaviera de pernambuco}

RESUMEN: El presente trabajo pretende analizar los registros de los movimientos de los trabajadores rurales y sus representaciones en el camino hacia la Justicia Laboral. Utilizamos demandas laborales del archivo del Tribunal Regional del Trabajo de la VI Región y registros policiales del Departamento de Orden Político y Social de Pernambuco, producida entre los años 1970 y 1980. El objetivo es pensar la memoria de la obra de los archivos constituidos por fuentes judiciales y policiales de los trabajadores rurales de la zona canavieira de Pernambuco. Las colecciones constituirán fuentes para el análisis de las experiencias de los asalariados y la construcción de una historia de los trabajadores en el campo.

PALABRAS CLAVE: Justicia, Trabajo, Archivo, Memoria.

\footnotetext{
* Doutoranda em História pela Universidade Federal de Pernambuco. Graduação em Licenciatura em História e Mestrado em História pela Universidade Federal de Pernambuco. Contato: Av. da Arquitetura, s/n, $11^{\circ}$ andar Centro de Filosofia e Ciências Humanas. CEP: 50740-550 - Recife - PE, Brasil. E-mail: andradecris13@gmail.com
} 


\section{Introdução}

A zona canavieira de Pernambuco foi ao longo da história do Brasil a área mais importante do Estado do ponto de vista da agricultura e, desde os tempos coloniais, foi grande produtora de açúcar. Os embates entre os trabalhadores rurais e agroindústria açucareira de Pernambuco levados aos tribunais vão compor litígios que produziram novas relações de trabalho no campo. Com o acionamento de dispositivos legais e a instauração de demandas coletivas, a memória do trabalho do campo passa a ser pensada a partir de espaços de luta e reivindicação por direitos.

Neste artigo buscamos analisar os registros dos movimentos dos trabalhadores rurais e suas representações a caminho da Justiça do Trabalho, pensando na constituição dos arquivos produzidos por meio dos embates com a agroindústria açucareira da zona canavieira de Pernambuco, entre as décadas de 1970 e 1980. Utilizamos para tal análise o cruzamento de fontes documentais do acervo de processos trabalhistas do Tribunal Regional do Trabalho (TRT) da 6 ${ }^{a}$ Região e prontuários arquivados no Departamento de Ordem Política e Social de Pernambuco (DOPS-PE) que mapeiam os conflitos levados aos tribunais pelos trabalhadores rurais em busca de melhores condições de vida e trabalho. O objetivo é pensar uma configuração desses registros dos trabalhadores e os mecanismos de vigilância que incidiam sobre estes, por meio das fontes judiciais e policiais produzidas durante o Regime CivilMilitar instalado de 1964 a 1985.

A instalação de Juntas de Conciliação e Julgamento na Zona Canavieira de Pernambuco na década de 1960 possibilitou o amplo recurso à Justiça do Trabalho pelos trabalhadores rurais do mundo do açúcar. A zona canavieira é marcada pela organização e movimento dos trabalhadores rurais, em Ligas Camponesas e Sindicatos ${ }^{1}$, que também estabeleceram relações com grandes mobilizações de trabalhadores rurais do país entre 1955 e $1964^{2}$. As Juntas permitiam o acesso à primeira instância da Justiça e os trabalhadores rurais recorriam cada vez mais à Justiça do Trabalho.

Os embates judiciais ocorridos nas Juntas de Conciliação e Julgamento da zona canavieira de Pernambuco vão colocar em lados opostos os trabalhadores rurais e os proprietários da agroindústria açucareira de Pernambuco. 


\section{Representação trabalhista no campo}

Os sindicatos rurais enquanto órgãos de representação atuantes criam um clima favorável às estratégias de resistência que resultam em melhores condições de trabalho no engenho. Essa representação ajuda efetivamente o trabalhador orientando-o para um enfrentamento no tribunal. Assim como, a ausência de um sindicato empenhado da defesa do trabalhador rural transfere a ameaça dos limites do engenho para o âmbito regional3. As ameaças que se dão nos limites do engenho são então ampliadas para um conjunto de engenhos e usinas da região.

Os movimentos representativos dos trabalhadores atuaram intensamente no período anterior à deflagração do Golpe Civil-Militar de 1964. Com a instauração do regime civilmilitar visualizamos o impedimento do sindicato em mobilizar os trabalhadores diretamente nos engenhos. Este contato depende, portanto, da iniciativa do trabalhador em procurá-lo. Se o empregador consegue através da intimidação manter os trabalhadores afastados do Sindicato resulta na anulação da ação sindical dentro do engenho ou "uma ação muito remota" ${ }^{4}$. A individualização da ameaça também repercute em todas as condições de evitar que o enfrentamento se transfira para um tribunal. Sob coação, o patronato consegue manter o conflito no "chão do engenho" e assim evita que o enfrentamento se desenvolva em embates judiciais 5 .

A entrada do trabalhador rural no mundo legal da representatividade política é marcada pela maior atuação dos sindicatos e o aumento na procura dos registrados/fichados pelos departamentos jurídicos, que "representavam o caminho de entrada do trabalhador no mundo legal. As consultas oferecidas pelos advogados sindicais constituíam um espaço onde os sindicalizados exerciam o papel de cidadãos-trabalhadores"6. A quantidade de processos instaurados pelos trabalhadores nas Juntas Trabalhistas constitui informações que nos permitiram conhecer a atuação dos sindicatos no tocante à organização dos trabalhadores na luta por direitos, a apropriação e a demanda destes novos espaços de direito no campo.

A importância dos Sindicatos na conjuntura das relações de trabalho durante o regime civil-militar possibilitou a sua utilização como instrumento mais eficaz na constituição de um espaço de luta no campo, mesmo que sob vigilância da polícia política, transformando a resistência individualizada em reivindicações coletivas por melhores condições de vida na zona canavieira de Pernambuco. A partir da década de 1960 institui-se o processo de 
sindicalização das relações trabalhistas no campo. A Associação Sindical das Classes Rurais foi regulamentada em 1963 pelo Estatuto do Trabalhador Rural (ETR). Em seu Art. 144, o ETR delimitou a associação sindical para "fins de estudo, defesa, coordenação de seus interesses econômicos ou profissionais, de todos os que, como empregados, ou empregadores, exerçam atividades ou profissão rural"7. Estas organizações de classe no campo tinham como prerrogativas a representatividade dos trabalhadores rurais perante as autoridades judiciárias e administrativas, com autonomia para celebrar convenções coletivas de trabalho.

A Portaria 209-A em 1962 havia instituído a sindicalização rural e neste mesmo ano, 69 sindicatos de trabalhadores rurais foram reconhecidos no país. Estes dispositivos alteravam as representações dos trabalhadores no mundo legal, passavam a ser acionados e legitimavam novas possibilidades de reivindicações e lutas por direitos e melhores de condições de vida no campo.

Durante a década de 1960 visualizamos a instalação das Juntas de Conciliação e Julgamento na Zona Canavieira de Pernambuco. Esses espaços trabalhistas institucionais permitiam o acesso à Justiça em primeira instância aos trabalhadores rurais que reivindicavam o não cumprimento e desrespeitos a seus direitos trabalhistas conquistados por meio de dispositivos como o Estatuto do Trabalhador Rural de 1963 e adequações das relações rurais na Consolidação das Leis Trabalhistas de 1943.

Os Sindicatos Rurais da Zona Canavieira de Pernambuco recebiam estes trabalhadores em suas instalações e providenciavam petições iniciais para a abertura dos processos trabalhistas nas respectivas Juntas. Estes trabalhadores rurais eram acompanhados por advogados sindicais ao longo do processo e tinham suas presenças registradas em várias peças dos autos trabalhistas.

\section{Memória do trabalho no campo}

Os processos trabalhistas utilizados para pensar as relações de trabalho no campo compõem o acervo do Projeto Memória e História ${ }^{8}$. Os registros dos embates trabalhistas representam a possibilidade de reconstrução das relações de trabalho em Pernambuco, após a década de 1960. São processos que apresentam as reclamações às Juntas de Conciliação e Julgamento pelos assalariados, que procuram seus direitos e manifestam insatisfações diante dos contratos trabalhistas. 
Esses processos judiciais constituem parte importante da história da Justiça do Trabalho no Brasil, eles são fontes essenciais para o conhecimento das iniciativas em defesa dos direitos dos trabalhadores. A utilização dos processos da Justiça do Trabalho como fonte de pesquisa na produção historiográfica é recente. Arquivistas, historiadores e magistrados compõem o conjunto de pesquisadores preocupados com o destino da memória do trabalho.

Acreditamos no potencial da documentação judiciária para a análise da experiência dos assalariados como objeto de reflexão para a construção da história dos trabalhadores. $\mathrm{O}$ historiador Sidney Chalhoub, em $O$ conhecimento da História, o Direito à Memória e os Arquivos Judiciais, discute a importância dos arquivos judiciários no Brasil e a utilização de seus processos na construção do conhecimento da história. O autor chama a atenção dos historiadores para a totalidade dos documentos produzidos pelo Poder Judiciário. Ele faz uso de processos do Tribunal do Júri do Rio de Janeiro para estudar a história dos escravos com uma enorme riqueza de detalhes ${ }^{9}$.

Um dos artigos que trata a contribuição do campo jurídico para a pesquisa histórica é Trabalho, Direitos e Justiça no Brasil, elaborado por Silvia Hunold Lara. A autora reflete sobre a aproximação entre História e Direito, que resulta cada vez mais num interesse crescente de pesquisadores pelos acervos documentais produzidos no âmbito da Justiça e por sua preservação. Silvia Lara pontua o movimento de procura, realizado por muitos pesquisadores, das fontes judiciais como "via de acesso ao cotidiano e ao universo de homens e mulheres cujas vozes não haviam sido registradas nos chamados documentos oficiais(do Executivo ou Legislativo), ou em outras fontes, como os jornais."

Fernando Teixeira da Silva vai chamar a atenção para a preservação dos autos findos. No artigo $O$ historiador e os processos trabalhistas, o autor considera esses documentos repletos de significados históricos, entre suas ambiguidades e porosidades. Ele vai chamar a atenção para os interesses dos pesquisadores nos processos trabalhistas, principalmente pelos assuntos tratados e pelos documentos anexados aos autos, "a classificação tipológica do documento não pode ser o mais importante para o historiador. Ou seja, um processo trabalhista diz muito mais que o discurso maculado" ${ }^{11}$.

É recente também a preocupação de políticas públicas de gestão documental a preservação dos processos judiciais no âmbito do Poder Judiciário do Trabalho. Um tema polêmico que tem provocado debate no cenário público e resultado em trabalhos apresentados em diversos simpósios, conferências e encontros. A destruição em massa desses documentos, acobertada pela Lei n. 5.925, impede o acesso dos cidadãos aos elementos de prova e às 
informações que os processos complementam. Em $O$ Historiador e os processos trabalhistas, o autor pontua o interesse dos pesquisadores nos processos trabalhistas, principalmente pelos assuntos tratados e pelos documentos anexados aos autos, "a classificação tipológica do documento não pode ser o mais importante para o historiador. Ou seja, um processo trabalhista diz muito mais que o discurso maculado" ${ }^{\text {.2 }}$.

A falta de espaço físico vai de encontro com a compreensão da preservação dos processos judiciais. A guarda adequada desses documentos públicos entende a conservação hígida destes documentos judiciais sem comprometer sua utilização para produção de prova e fins de pesquisa. Este direito de acesso à informação só pode ser concretizado quando este acervo, que contem a documentação relativa ao Poder Judiciário, estiver preservado e disponibilizar condições de ser acessado. A juíza Magda Biavaschi acredita que o Estado tem o dever de preservar esta documentação e garantir o acesso a investigação adequada assegurando a integridade documental dos processos judiciais. Assim, a preservação desses documentos judiciais é dever do Estado no sentido de direito à jurisdição do acesso à prova. A magistrada ressalta a importância das fontes históricas para a preservação da memória e como direito à jurisdição, nele compreendido o direito à prova. Para Biavaschi ${ }^{13}$, aprofundar o debate é fundamental para a preservação da Memória da Justiça do Trabalho como direito do cidadão.

O expressivo número de processos eliminados dificulta algumas pesquisas nestas fontes primárias. A ideia de preservar deve ser pensada como dever do Estado e direito do cidadão. A constituição da República de 1988 permite compreender a guarda dos documentos públicos como um direito do cidadão em relação à preservação da memória da Justiça do Trabalho e o acesso dos cidadãos aos elementos de prova que os processos contemplam. No artigo 23 no capítulo III e IV da Constituição Federal encontra-se a responsabilidade dada à Administração Pública em cuidar da gestão da documentação governamental e viabilizar as devidas providências para aqueles que necessitarem da sua consulta. Esta proteção dos documentos com valor histórico que compõem o patrimônio documental nacional está circunscrita na tutela do patrimônio cultural brasileiro.

O caminho dos trabalhadores rurais à Justiça também foi mapeado por instâncias da polícia política de Pernambuco. O uso dos Prontuários do Departamento de Ordem e Política de Pernambuco são pensados como uma produção arquivística do Estado autoritário exercendo seu poder de vigilância sobre o movimento dos trabalhadores do campo. As coleções documentais registradas e arquivadas por esse órgão ativo durante o regime Civil- 
Militar nos embasam sobre as perspectivas que o Estado construía a cerca da organização dos trabalhadores.

Encontramos prontuários específicos sobre a vigilâncias das ações no campo reunidos em pastas como P. 1.352 - "Contag", Fundo SSP 1607 - "Sindicatos dos Trabalhadores Rurais", P. 26.679 - "SORPE”, P. 28.688 - "Fetape” e Fundo SSP 26.993 - "Movimento da Zona Canavieira", entre outros. A reunião de documentos identificados como confidenciais, secretos e sigilosos eram apreendidos e arquivados para monitoramento das ações desses trabalhadores durante os tempos de repressão. A pesquisa com a documentação do DOPS-PE depositada no Arquivo Público Estadual de Pernambuco possibilita estudar esta vigilância e monitoramento.

Os documentos registrados estão localizados no prontuário de número 31.496 do arquivo DOPS-PE. Este prontuário nos mostra o exercício de vigilância sobre os movimentos dos trabalhadores em suas representações. Encontramos dentre os ofícios arquivados, o apreendimento de folhetos que circulavam pela região canavieira as notificações de circular sobre o processo de luta da campanha salarial vigente no ano de 1980. Os Dissídios levados ao Tribunal Regional do Trabalho da 6 ${ }^{a}$ Região nos anos e 1980 e 1981 foram intensamente mapeado pela polícia política. As publicações veiculadas nos periódicos da imprensa local e as atas de Julgamento do Tribunal foram arquivadas no prontuário funcional que reunia documentos sobre a Federação dos Trabalhadores na Agricultura do Estado de Pernambuco Fetape e Sindicatos dos Trabalhadores da Zona Canavieira de Pernambuco.

O ofício encaminhado para o IV Exército sobre a Campanha Salarial dos Trabalhadores dos Sindicatos Rurais da Zona Canavieira de Pernambuco mapeava as ações e listava as pessoas presentes na ocasião do julgamento, com as respectivas identificações institucionais. O informe da Delegacia Regional do Trabalho sinalizava com o carimbo "Confidencial" ao final da página e compunha a coletânia de documentos do Prontuário intitulado "Movimento Camponês", de número 31.496.

A informação constitui um tipo de poder e a rede formada pela coleta de dados que mapeia os grupos que apresentavam uma instabilidade para o regime constitui um aparato de controle para sustentabilidade das práticas de repressão. Segundo a pesquisadora Marcilia Gama, a informação é entendida como "um poder disciplinar, cujos efeitos se percebem no cotidiano, nas práticas e rotinas de investigação, no interrogatório policial, nos assentamentos e registros nos arquivos"14. O governo instalado de 1964 a 1985 com o Golpe Civil-Militar é paramentado no controle da sociedade e na defesa de uma definição de Segurança Nacional, 
enquanto conceito elaborado pela Escola Superior de Guerra ${ }^{15}$. Para operacionalizar as práticas de controle e repressão, o regime promove um extenso setor de levantamento de informações, como afirma Silva:

\begin{abstract}
É nesse sentido que se coloca o poder da informação sobre pessoas e fatos e os efeitos que a posse desses "saberes" irá proporcionar, na medida em que dela o governo militar tomará posso no intuito de por em prática a "limpeza" no tecido social, eliminando toda e qualquer manifestação de oposição ao regime. Nesse sentido a coleta, manuseio, disseminação das "provas" de combate ao comunismo e corrupção são forjadas no universo dos arquivos policiais, nas esferas dos órgãos de informação e segurança, como representações de um crime que deveria ser extirpardo a qualquer custo da sociedade. ${ }^{16}$
\end{abstract}

Os arquivos judiciais e policiais que registram as reivindicações dos trabalhadores rurais por meio dos seus sindicatos constituem lugares de memória para discutir os paradigmas de registro ${ }^{17}$. É preciso discutir o arquivo enquanto espaço de escolhas e seleções e os documentos arquivados pela Justiça e pela Polícia Política entre as décadas de 1960 e 1980, problematizando seus processos de arquivamento. O trabalhador rural é pensando como um sujeito que preocupa a estabilidade do regime de repressão instaurado no país. A vigilância e repressão sob este sujeito social é observada por meio da vasta documentação salvaguardada dos registros de seus movimentos reivindicatórios, sendo sinalizados principalmente por seus órgãos de representação. Discutir como os documentos foram arquivados pela Justiça do Trabalho e pelo Departamento de Ordem Política e Social permite a reflexão da categoria trabalho rural e das lutas por melhores condições de vida no campo. A zona canavieira é entendida como um "zona de perigo" e esta percepção da Polícia Política em Pernambuco vai constituir catalogações em seus arquivos de registro.

Os Sindicatos dos Trabalhadores Rurais da zona canavieira de Pernambuco, enquanto mobilização dos trabalhadores e representação de suas demandas no caminho à Justiça do Trabalho, foram alvo constante das políticas de controle e repressão instauradas pelo regime ditatorial em nome do que estes definiam como a Segurança Nacional. Os arquivos da polícia política em Pernambuco enquadravam, investigavam e perseguiam as referências de movimentos no campo e suas formas de organização. Para os trabalhadores rurais do final da década de 1970 e início da década de 1980, o espaço alcançado com a representatividade dos STRs e a produção de dispositivos produzidos por meio das demandas coletivas de classe constituíam efetivos enfrentamentos contra a agroindústria açucareira. 


\section{Embates trabalhistas na zona canavieira de Pernambuco}

No dia 15 de fevereiro de 1982, o trabalhador rural Severino Afonso de Lima comparece a Audiência de Instrução e Julgamento (AIJ) do seu processo contra o Engenho Pirapama. Às 08:50 da referida data é aberta a audiência na Junta de Conciliação e Julgamento de Jaboatão - PE, com endereço em Rua Visconde de Rio Branco 440, $1^{\circ}$ andar, sinalizando a presença do Sr. Presidente Dr. João Batista da Silva e dos Srs. Vogais Deoclécio da Siva Mendonça e Braulio de Oliveira Barros, representantes empregadores e empregados respectivamente ${ }^{18}$.

Nas atas das Audiências de Instrução e Julgamento (AIJ) é notável a contínua presença destes representantes sindicais por meio da identificação "Juízes Vogais". Os senhores Vogais, como eram chamados pelo Presidente da Junta, eram identificados no início da sessão destacando às respectivas presenças ao lado dos trabalhadores rurais enquanto reclamantes do processo instaurado. Os advogados sindicais acompanhavam então os interrogatórios e depoimentos dos trabalhadores até o fim das sessões, assinando as atas redigidas e lavradas pelo chefe de Secretaria das Juntas de Conciliação e Julgamento ao fim de cada peça.

O tramite processual na justiça trabalhista é padronizado para transmitir impessoalidade ao Poder Judiciário na mediação dos conflitos. Os ritos seguidos pelo processo são pré-estabelecidos pelas determinações da Secretaria da Junta e o trabalhador, no papel de reclamante, inicia esta tramitação com depósito de documentos e preenchimento de Termos que certificam a abertura, a notificação e realização da primeira audiência do processo.

Este primeiro contato com a Justiça é feito pelo encaminhamento dos sindicatos rurais na grande maioria dos processos impetrados na Justiça Trabalhista ao longo regime civilmilitar. Exercendo sua função de representação, os sindicatos rurais direcionam e legitimam a garantia de acesso à Justiça no campo através da extensiva impetração de processos individuais e coletivos contra a agroindústria açucareira do Nordeste ${ }^{19}$. 
Processos Impetrados por Trabalhadores Rurais na Junta de Conciliação e Julgamento de Jaboatão 1980 (total de 102 processos)

Sindicatos:

Sindicato dos Trabalhadores Rurais de Jaboatão

Sindicato dos Trabalhadores Rurais de Vitória de Santo Antão

Sindicato dos Trabalhadores Rurais de Glória do Goitá

Sindicato dos Trabalhadores Rurais de Gravatá

Sindicato dos Trabalhadores Rurais de Moreno

TOTAL

\begin{tabular}{|c|c|}
\hline $\mathrm{N}^{\mathrm{o}}$ & $\%$ \\
\hline 34 & $33,66 \%$ \\
\hline 28 & $27,72 \%$ \\
\hline 2 & $1,9 \%$ \\
\hline 2 & $1,9 \%$ \\
\hline 18 & $17,82 \%$ \\
\hline 84 & $83,16 \%$ \\
\hline
\end{tabular}

(do total de 102)

Os embates jurídicos possibilitaram espaços de reivindicações e lutas conquistados pelos trabalhadores do açúcar. No entanto, as relações entre empregado-empregadores não se dão de forma tão conciliatória fora das Juntas. Em muitos dos processos trabalhistas consultados é possível perceber na fala do trabalhador o depoimento da violência sofrida na busca pelo cumprimento de seus direitos trabalhistas no campo.

O caso do Sr. Antônio Francisco da Silva, descrito como brasileiro, casado e rurícola, testemunha o "violento espancamento" que sofreu do Fiscal de Campo, do engenho em que trabalhava e morava. ${ }^{20} \mathrm{O}$ acontecimento foi veiculado na mídia impressa local sob o título “Trabalhador é surrado para assinar folha” (Jornal do Comércio, 8 de janeiro de 1979).

Analisar as relações de trabalho no campo por meio dos processos trabalhistas nos possibilitou perceber como o próprio trâmite judicial constituía uma estratégia possível de luta para o trabalhador rural frente a agroindústria açucareira e como as causas procedentes nas Juntas de Conciliação e Julgamento de Jaboatão incentivavam os homens do campo a enfrentar os senhores de engenho no palco judicial, revelando as situações de violência como termos para o fim da relação de trabalho e possíveis reparações sociais.

A Justiça do Trabalho, enquanto órgão do Poder Judiciário, representou uma das únicas opções de luta numa conjuntura de repressão estabelecida após 1964. O embate judicial constituía a possibilidade de dirimir os conflitos do campo e reparar de alguma forma as imensas injustiças sociais e trabalhistas do mundo rural. 
Ao analisar as relações de trabalho no mundo rural foi possível observar o modo como estes atores sociais operaram com os dispositivos legais como mecanismos de defesa dos seus interesses frente aos embates judiciais.

A relevância da discussão sobre as relações de trabalho é pertinente no contexto atual de regime democrático onde as mobilizações e reivindicações por melhores condições de vida eclodem por todo o território do país, onde as greves e paralisações dos trabalhadores são utilizadas como instrumentos democráticos na exigência pelo cumprimento de garantias trabalhistas, mas por vezes são retratadas e apropriadas pela opinião pública como entraves a prestação de serviços "essenciais". A greve, ao longo da história do trabalho, vai se situar entre o delito e o direito. É a apropriação destes instrumentos enquanto direitos que marca a retomada de luta por melhores condições de vida na zona canavieira de Pernambuco.

\section{Notas}

1 MONTENEGRO, Antonio Torres. Ligas Camponesas e Sindicatos Rurais em tempo de revolução. In: DELGADO, Lucilia de Almeida de Neves; FERREIRA, Jorge (Org.). O Brasil republicano. O tempo da experiência democrática: da democratização de 1945 ao golpe civil-militar de 1964. V.03. Rio de Janeiro: Civilização Brasileira, 2003.

2 PORFÍRIO, Pablo F. de A. Medo, comunismo e revolução: Pernambuco (1959-1964). Recife: Ed. Universitária, UFPE, 2009.

3 SIGAUD, L. Greve nos Engenhos. Rio de Janeiro: Paz e Terra, 1980. p.93

${ }^{4}$ SIGAUD, L. Greve nos Engenhos. Rio de Janeiro: Paz e Terra, 1980. p. 93

5 A expressão "chão do engenho" é utilizada em oposição ao já conhecido "chão da fábrica" recorrente nas análises dos mundos do trabalho

${ }^{6}$ CORREA, Larissa Trabalhadores têxteis e metalúrgicos a caminho da Justiça do Trabalho: leis e direitos na cidade de São Paulo, 1955 a 1964. Dissertação de Mestrado apresentada ao Departamento de História do Instituto de Filosofia e Ciências Humanas da Universidade Estadual de Campinas. 2007, p.37

7 Art. 144, Lei n. 4.214, de 02 de Março de 1963. Disponível em: http://www010.dataprev.gov.br/sislex/paginas/42/1963/4214.htm

${ }_{8}$ O Projeto Memória e História resulta do convênio entre o Tribunal Regional do Trabalho da $6^{\text {a }}$ Região e o Departamento de História da Universidade Federal de Pernambuco, UFPE, coordenado pelo historiador Antônio Torres Montenegro e tem a professora Vera Acioli como Coordenadora Técnica.

9 CHALHOUB, Visões de liberdade: uma história das últimas décadas da escravidão na corte. São Paulo: Companhia das Letras, 1990.

${ }^{10}$ LARA, Silvia Hunold. Trabalho, direitos e justiça no Brasil. In: SCHMIDT, B.(Org.) História, Justiça e Trabalho. São Leopoldo: Oikos, 2010, p. 108

${ }^{11}$ SILVA, Fernando Teixeira da. O Historiador e os Processos Trabalhistas no Brasil. In: II Encontro Nacional da Memória da Justiça do Trabalho (2:2008: Campinas, SP) - São Paulo: Ltr, 2008.

${ }^{12}$ SILVA, Fernando Teixeira da. O Historiador e os Processos Trabalhistas no Brasil. In: II Encontro Nacional da Memória da Justiça do Trabalho (2:2008: Campinas, SP) - São Paulo: Ltr, 2008.

13 BIAVASCHI, Magda Barros. Justiça do Trabalho e Preservação das Fontes Históricas: Preservar é direito do cidadão e dever do Estado. In: III Encontro Nacional da Memória da Justiça do Trabalho - Recife: Nossa Livraria, 2008. P.43

14 (SILVA, Marcilia Gama Informação, Repressão e Memória: A construção do Estado de exceção no Brasil na perspectiva do DOPS-PE. Recife: Tese de Doutorado, UFPE. 2007., p.15).

15 SILVA, Marcilia Gama Informação, Repressão e Memória: A construção do Estado de exceção no Brasil na perspectiva do DOPS-PE. Recife: Tese de Doutorado, UFPE. 2007. p.36

16 SILVA, Marcilia Gama. Informação, Repressão e Memória: A construção do Estado de exceção no Brasil na perspectiva do DOPS-PE. Recife: Tese de Doutorado, UFPE. 2007 p.38 
17 FARGE, Arlette. O sabor do arquivo. São Paulo: Edusp, 2009.

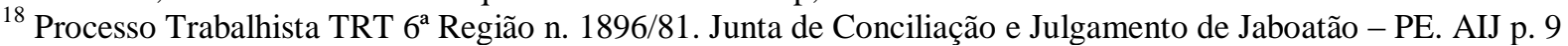

19 Entre 1979 e 1980, aproximadamente 80\% dos processos impetrados por trabalhadores rurais contra os engenhos e usinas da Zona da Mata de Pernambuco foram intermediados pelos sindicatos rurais da região. RAPOSO, C. JUSTIÇA E RELAÇÕES DE TRABALHO NA ZONA DA MATA DE PERNAMBUCO: Espaços e possibilidades de reivindicações e lutas por direitos (1979-1985). Dissertação de Mestrado apresentada ao Programa de Pós-graduação em História da Universidade Federal de Pernambuco - UFPE, 2013.)

${ }^{20}$ Ação n09/79, impetrada a Junta de Conciliação e Julgamento de Jaboatão.

\section{Referências Bibliográficas}

ABREU E LIMA, Maria do Socorro. Construindo o Sindicalismo Rural: Lutas, Partidos, Projetos. Recife: Editora Universitária da UFPE: Editora Oito de Março, 2005.

ACIOLI, Vera Lúcia Costa; GUIMARÃES NETO, Regina Beatriz; MONTENEGRO, Antonio Torres. (Orgs.). História, Cultura, Trabalho: questões da contemporaneidade. Recife: Ed. Universitária da UFPE, 2011.

ANDRADE, Manuel Correia de. A Terra e o homem no Nordeste. São Paulo: Cortez, 2005.

BATALHA, Cláudio H. M. Os desafios atuais da História do Trabalho. Anos 90, Porto Alegre, v.13, n. 23-24, jan./dez. 2006.

BIAVASCHI, Magda Barros. Justiça do Trabalho e Preservação das Fontes Históricas: Preservar é direito do cidadão e dever do Estado. In: III Encontro Nacional da Memória da Justiça do Trabalho - Recife: Nossa Livraria, 2008. P.43

CARVALHO, José Murilo de. Cidadania no Brasil: o longo caminho. $14^{\mathrm{a}}$ Ed. Rio de Janeiro: Civilização Brasileira, 2011.

CHALHOUB, Sidney. Trabalho, lar e botequim: o cotidiano dos trabalhadores no Rio de Janeiro da belle époque. Campinas, SP: Editora UNICAMP, 2001.

Visões de liberdade: uma história das últimas décadas da escravidão na corte. São Paulo: Companhia das Letras, 1990.

CORRÊA, Larissa Rosa. Trabalhadores têxteis e metalúrgicos a caminho da Justiça do Trabalho: leis e direitos na cidade de São Paulo, 1955 a 1964. Dissertação de Mestrado apresentada ao Departamento de História do Instituto de Filosofia e Ciências Humanas da Universidade Estadual de Campinas. 2007.

DABAT, Christine Paulette Yves Rufino. Moradores de Engenho: Estudo sobre as relações de trabalho e condições de vida dos trabalhadores rurais na zona canavieira de Pernambuco, segundo a literatura, a academia e os próprios atores sociais. Recife, 2003. Tese de Doutorado em História, Universidade Federal de Pernambuco.

ESPERANÇA, Clarice. A greve de Chumbo. O movimento de resistência dos trabalhadores da Empresa Jornalística Caldas Junior. Porto Alegre: Dissertação de Mestrado, 2007.

FARGE, Arlette. O sabor do arquivo. São Paulo: Edusp, 2009.

FORTES, Alexandre. Na luta por direitos: Estudos recentes em história social do trabalho. Campinas: Editora Unicamp, 1999.

FOUCAULT, Michel. A verdade e as formas jurídicas. Rio de Janeiro: Nau, 2005. . Microfísica do Poder. Rio de Janeiro: Edições Graal, 1979.

GOHN, Maria da Glória. Movimentos sociais na atualidade: manifestações e categorias analíticas. Petrópolis, RJ: Vozes, 2013

GOMES, Angela de Castro. A invenção do trabalhismo 2ed. Rio de Janeiro: Relume Dumará, 1994. 
GUIMARÃES NETO, Regina Beatriz. Cidades da mineração: memórias e práticas culturais. Cuiabá: EDUFMT, 2006.

. Vira mundo, vira mundo: trajetórias nômades. As

cidades na Amazônia. In: Projeto História: revista do programa de Estudos Pós-Graduados em História e do Departamento de História da Pontifícia Universidade Católica de São Paulo.Vol.27, São Paulo: EDUC, 2003, p.49 - 69.

LARA, Silvia Hunold. Direitos e Justiça no Brasil: ensaios de história social. Campinas, SP: Editora UNICAMP, 2006. . Trabalho, direitos e justiça no Brasil. In: SCHMIDT, B.(Org.)

História, Justiça e Trabalho. São Leopoldo: Oikos, 2010, p. 108

KOSELLECK, Reinhart. Futuro Passado: Contribuição à semântica dos tempos históricos. Rio de Janeiro: Contraponto, 2006.

MARTINS, José de Souza. A política do Brasil: lúmpen e místico. São Paulo: Contexto, 2011.

. Os camponeses e a política no Brasil. As lutas sociais no campo e seu lugar no processo politico. Petropolis: Vozes, 1981.

MONTENEGRO, Antônio Torres. História, metodologia, memória. São Paulo: Contexto, 2010.

Ligas Camponesas e Sindicatos Rurais em tempo de revolução. In: DELGADO, Lucilia de Almeida Neves; FERREIRA, Jorge (Org.). O Brasil republicano. O tempo da experiência democrática: da democratização de 1945 ao golpe civil-militar de 1964. V.03. Rio de Janeiro: Civilização Brasileira, 2003.

Produções do Medo: algumas trilhas. (1955-1964). In:

MONTENEGRO, A; REZENDE, A. GUIMARAES NETO, R. et al. (Orgs.). História: cultura e sentimento. Outras histórias do Brasil. Co-edição - Recife: Ed. Universitária da UFPE; Cuiabá: Ed. Da UFMT, 2008.

Trabalhadores rurais e Justiça do Trabalho em tempos de regime civil-militar. In: GOMES, Angela de Castro e TEIXEIRA, Fernando (Orgs.). A Justiça do Trabalho e sua história: direitos sociais e humanos dos trabalhadores no Brasil. Campina: Editora da Unicamp, 2013.

PAIDA, Zenilda. Trabalhador Rural. Conteúdo Jurídico, Brasilia - DF, 2012.

PALMEIRA, Moacir. Modernização, Estado e questão agrária. Estudos Avançados. 1989, vol.3, n.7, PP. 87-108.

PORFÍRIO, Pablo F. de A. Medo, comunismo e revolução: Pernambuco (1959-1964). Recife: Ed. Universitária, UFPE, 2009.

SCHIMIDT, Benito Bisso (Org.). Trabalho, justiça e direitos no Brasil. Pesquisa histórica e preservação das fontes.- São Leopoldo: Oikos, 2010.

SIGAUD, Lygia. Greve nos Engenhos. Rio de Janeiro: Paz e Terra, 1980.

Os Clandestinos e o Direitos: Estudos sobre trabalhadores da cana-deaçúcar de Pernambuco. São Paulo: Duas Cidades, 1979.

Armadilhas da honra e do perdão: usos sociais do direito na mata pernambucana. Mana, 10 (1), abr/2004. pp.131-163

SILVA, Fernando Teixeira da. O Historiador e os Processos Trabalhistas no Brasil. In: II Encontro Nacional da Memória da Justiça do Trabalho (2:2008: Campinas, SP) - São Paulo: Ltr, 2008.

SILVA, Marcília Gama. Cultura e Memória - História e Trabalho. Gestão documental no TRT6: Um apelo à História e à Memória. In: ACIOLI, V., GUIMARAES, R., 
MONTENEGRO, A. História, cultura, trabalho: questões da contemporaneidade. Recife: Ed. Universitária da UFPE, 2011.

Informação, Repressão e Memória: A construção do Estado de exceção no Brasil na perspectiva do DOPS-PE. Recife: Tese de Doutorado, UFPE. 2007.

VEYNE, Paul M. Como se escreve a história. Lisboa: Edições 